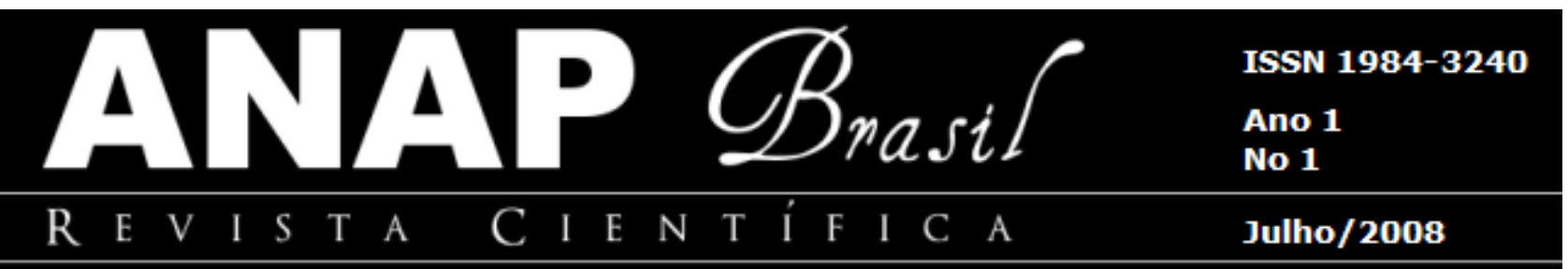

\title{
NORMAS PARA PUBLICAR NA REVISTA ANAP BRASIL
}

\section{CRITÉRIOS PARA SELEÇÃO}

Os artigos deverão ser encaminhados para Comissão Avaliadora da ANAP, através do e-mail anapbrasil@amigosdanatureza.org.br.

A seleção dos artigos observará o conjunto: título; a contextualização do conteúdo com o eixo escolhido; e a qualidade do levantamento teórico e bibliográfico.

Caso o artigo seja selecionado, o (s) autor (es) será (serão) avisado (s) por email.

\section{FORMATAÇÃO DO TRABALHO}

O texto completo (inclui a bibliografia) deverá conter de 6 a 25 páginas, tamanho A4, normas da ABNT.

O texto deverá estar digitado em Word e deverá ser encaminhado com nome curto (sem espaços, sem acentos, sem cê-cedilha). Exemplo: impactos.doc

A formatação do trabalho deverá respeitar as seguintes orientações: papel A4, letra Arial, tamanho 12, espaçamento 1,5 entre linhas. Margem superior de $2 \mathrm{~cm}$, inferior de $2 \mathrm{~cm}$, direita de $2 \mathrm{~cm}$ e esquerda de $2 \mathrm{~cm}$. Poderão ser utilizadas fotos, gráficos e tabelas, desde que devidamente indicada a fonte original.

As folhas devem ser numeradas do lado direito, no canto inferior da página.

Título, centralizado na primeira linha, com letra de tamanho 16, maiúscula, em negrito.

Pule 1 (uma) linha, e escreva o nome do autor alinhado à direita, com letra de tamanho 14, minúscula em negrito. Em rodapé sua formação acadêmica, instituição e/ou cargo. Deixe uma linha em branco e repita o procedimento se tiver outros autores.

Pule 1 (uma) linha e inicie o resumo em português (com máximo de 250 palavras). Pule uma linha e especifique a palavras-chave (até 3 palavras).

Pule 1 (uma) linha, iniciem o texto, concluindo o mesmo com a referencia bibliográfica. 


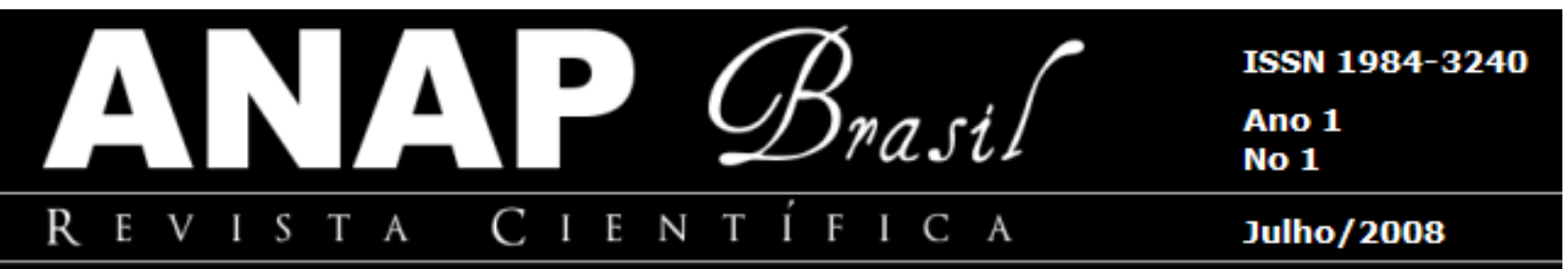

\title{
MODELO DO ARTIGO
}

\section{TÍTULO DO ARTIGO}

Nome do autor ${ }^{1}$

\author{
Nome do co-autor ${ }^{2}$
}

Nome do co-autor ${ }^{3}$

Nome do co-autor ${ }^{4}$

RESUMO: Poderá ter até 250 palavras, conforme NBR 6028, de novembro de 2003 (Informação e documentação -Resumo - Apresentação) - O resumo deve ressaltar o objetivo, o método, os resultados e as conclusões do documento. A ordem e a extensão destes itens dependem do tipo de resumo (informativo ou indicativo) e do tratamento que cada item recebe no documento original. O resumo deve ser composto de uma seqüência de frases concisas, afirmativas e não de enumeração de tópicos. Recomenda-se o uso de parágrafo único. A primeira frase deve ser significativa, explicando o tema principal do documento. A seguir, deve-se indicar a informação sobre a categoria do tratamento (memória, estudo de caso, análise da situação etc.). Deve-se usar o verbo na voz ativa e na terceira pessoa do singular. Devem-se evitar: a) símbolos e contrações que não sejam de uso corrente; b) fórmulas, equações, diagramas etc., que não sejam absolutamente necessários; quando seu emprego for imprescindível, defini-los na primeira vez que aparecerem.

\footnotetext{
Formação acadêmica, instituição e/ou cargo. E-mail.

${ }^{2}$ Formação acadêmica, instituição e/ou cargo. E-mail.

${ }^{3}$ Formação acadêmica, instituição e/ou cargo. E-mail.

${ }^{4}$ Formação acadêmica, instituição e/ou cargo. E-mail.
} 


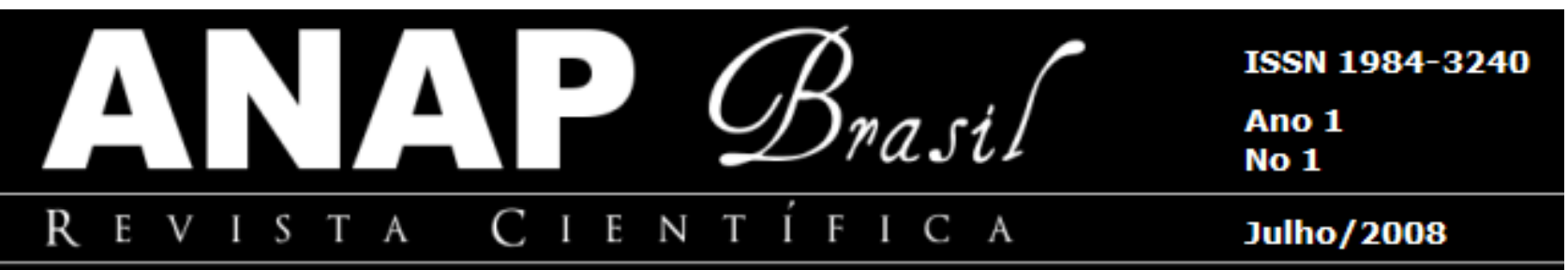

Palavras-chave: Primeira. Segunda. Terceira.

\section{ESTRUTURA}

Deverá seguir as determinações das NBR 6022, de maio de 2003 (Informação e documentação - Artigo em publicação periódica científica impressa - Apresentação). Os elementos textuais constituem-se em: introdução, desenvolvimento e conclusão. Conforme a NBR 14724, 2002, deve-se usar a fonte 12 para o texto e para as referências. Para as citações longas, notas de rodapé, paginação, legendas das ilustrações e tabelas, usar tamanho menor (fonte 10).

Para as citações o autor deverá seguir a NBR 10520 (Informação e documentação - Citações em documentos - Apresentação). No caso das citações diretas com mais de três linhas, deve ter destaque de $4 \mathrm{~cm}$ do parágrafo. A fonte deve ser menor do que o texto. O espacejamento entre linhas deve ser simples. (NBR 14724, 2003).

\subsection{INTRODUÇÃO}

Parte inicial do artigo, onde devem constar a delimitação do assunto tratado, os objetivos da pesquisa e outros elementos necessários para situar o tema do artigo.

\subsection{DESENVOLVIMENTO}

Parte principal do artigo, que contém a exposição ordenada e pormenorizada do assunto tratado. Divide-se em seções e subseções, conforme a NBR 6024, que variam em função da abordagem do tema e do método. 


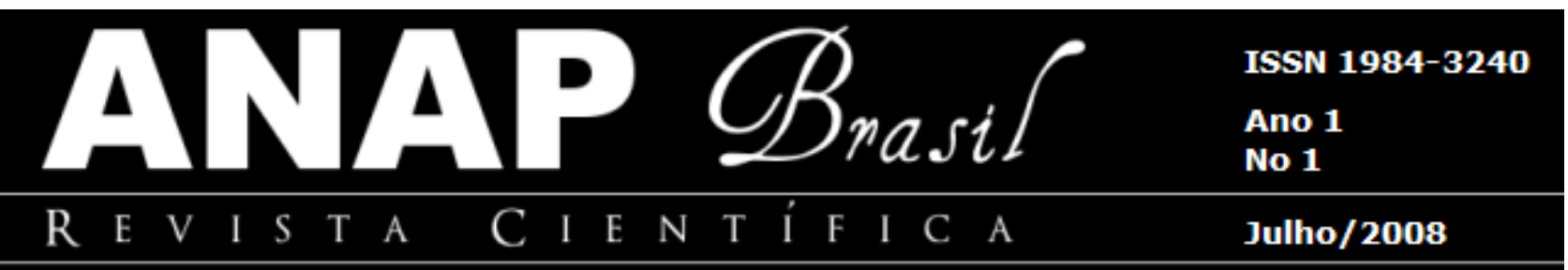

\subsection{CONCLUSÃO}

Parte final do artigo, na qual se apresentam as conclusões correspondentes aos objetivos e hipóteses.

\section{NUMERAÇÃO PROGRESSIVA}

A numeração progressiva deve ser apresentada conforme a NBR 6024. Destacam-se gradativamente os títulos das seções, utilizando os recursos de negrito, itálico ou grifo e redondo, caixa alta ou versal e outro. O título das seções (primárias, secundárias etc.) deve ser colocado após sua numeração, dele separado por um espaço. O texto deve iniciar-se em outra linha.

\section{ILUSTRAÇÕES}

Qualquer que seja seu tipo (desenhos, esquemas, fluxogramas, fotografias, gráficos, mapas, organogramas, plantas, quadros, retratos e outros), sua identificação aparece na parte inferior, precedida da palavra designativa, seguida de seu número de ordem de ocorrência no texto, em algarismos arábicos, do respectivo título e/ou legenda explicativa de forma breve e clara, dispensando consulta ao texto, e da fonte. A ilustração deve ser inserida o mais próximo possível do trecho a que se refere, conforme o projeto gráfico.

\subsection{TABELA}




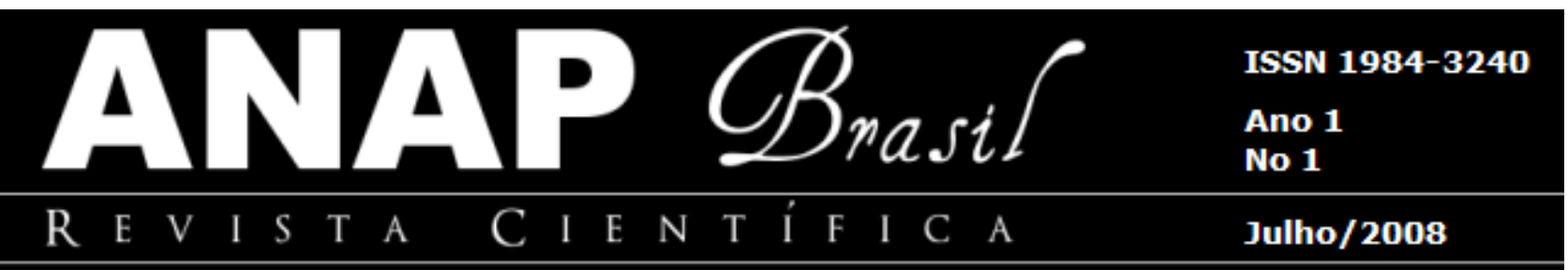

Para construir uma tabela consulte a norma para apresentação tabular do IBGE, 1993.

\subsubsection{Título}

Devem conter um título por extenso, inscrito no topo da tabela, para indicar a natureza e abrangência do seu conteúdo.

\subsubsection{Fonte}

A fonte deve ser colocada imediatamente abaixo da tabela em letra maiúscula / minúscula para indicar a autoridade dos dados e/ou informações da tabela, precedida da palavra Fonte.

\section{REFERENCIAL SEGUNDO A NBR 6023:2002}

O Título deverá ser centralizado. Deverá seguir as determinações da NBR 6023 de agosto de 2002 (Informação e documentação - Referências - Elaboração). As referências têm espaçamento simples e duplo entre si. As referências são apresentadas em ordem alfabética de autor e alinhadas somente à margem esquerda

\section{REFERÊNCIAS}




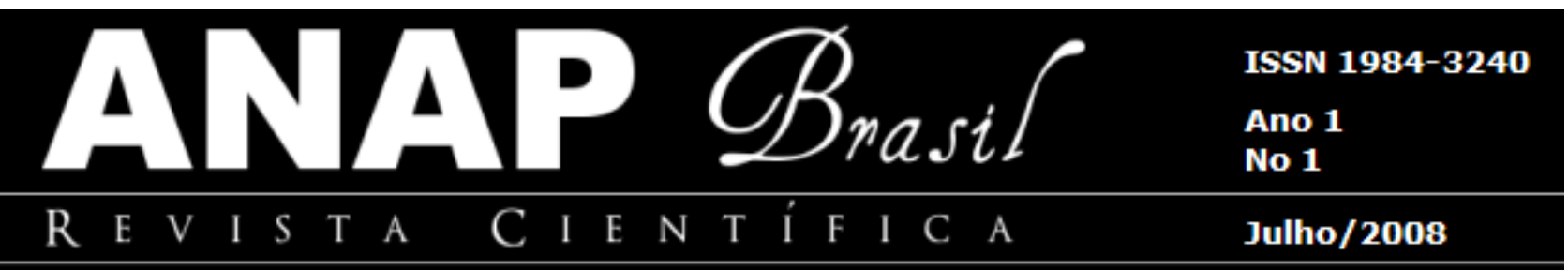

ABNT. NBR 6022: informação e documentação: artigo em publicação periódica científica impressa: apresentação. Rio de Janeiro, 2003. 5 p.

ABNT. NBR6023: informação e documentação: elaboração: referências. Rio de Janeiro, 2002. 24 p.

ABNT. NBR6024: Informação e documentação: numeração progressiva das seções de um documento. Rio de Janeiro, 2003. 3 p.

ABNT. NBR6028: resumos. Rio de Janeiro, 2003. 2 p.

ABNT. NBR10520: informação e documentação: citação em documentos. Rio de Janeiro, 2002. $7 \mathrm{p}$.

ABNT. NBR 14724: informação e documentação: trabalhos acadêmicos: apresentação. Rio de Janeiro, 2002. 6 p.

FRANÇA, Júnia Lessa et al. Manual para normalização de publicações tecnicocientificas. 6. ed. rev. e ampl. Belo Horizonte: UFMG, 2003. 230 p.

IBGE. Normas de apresentação tabular. 3. ed. 1993.

LAKATOS, Eva Maria; MARCONI, Marina de Andrade. Fundamentos de metodologia cientifica. 3. ed. rev. e ampl. São Paulo: Atlas, 1991. 270 p.

RELATÓRIO final de projetos de pesquisa: modelo de apresentação de artigo científico. Disponível em: <http://www.cav.udesc.br/anexol.doc.>. Acesso em: 03 dez. 2003. 